\title{
EXTENSIÓN Y CONSOLIDACIÓN DEL PODER EPISCOPAL SOBRE LAS IGLESIAS DE ÁLAVA DURANTE LOS SIGLOS XII-XIII: JERARQUÍA ADMINISTRATIVA Y CONFLICTIVIDAD LOCAL*
}

\author{
THE SPREAD AND CONSOLIDATION OF EPISCOPAL POWER \\ OVER THE CHURCHES OF ÁLAVA IN THE $12^{\text {th }}$ AND $13^{\text {th }}$ CENTURIES: \\ ADMINISTRATIVE HIERARCHY AND LOCAL CONFLICT
}

\author{
EGOITZ ALFARO SUESCUN \\ Universidad del País Vasco / Euskal Herriko Unibertsitatea \\ https://orcid.org/0000-0002-7617-0490
}

\begin{abstract}
Resumen: En el texto se analiza la extensión que el obispado de Calahorra, durante los siglos XII-XIII y a través de sus iglesias, llevó a cabo en el ámbito local de Álava. Las diferentes escalas de análisis muestran realidades diferentes en el proceso. A nivel macro parece que se implantó una estructura organizativa básica, basada en el esquema parroquia $<$ arciprestazgo < arcedianato < obispado, en la primera mitad del siglo XII. A nivel micro, sin embargo, la presencia de esta jerarquía administrativa no supuso una afirmación paralela e inmediata del poder episcopal sobre las iglesias locales. Los documentos evidencian la conflictividad entre los actores que controlaban estos templos y sus rentas, así como los tres grandes obstáculos con los que tuvo que lidiar la diócesis de Calahorra en su expansión: el control monasterial de las iglesias y sus rentas, la devolución de préstamos a la nobleza y los problemas en el cobro de los censos eclesiásticos.
\end{abstract}

Palabras clave: plena Edad Media; diócesis de Calahorra; poderes nobiliarios; monasterios; iglesia propia; parroquia.

Abstract: This paper analyses the growth of the bishopric of Calahorra in the Álava region, northcentral Iberia, during the $12^{\text {th }}$ and $13^{\text {th }}$ centuries. The different scales of analysis reveal distinct realities within the process. On a macro-level it seems that a basic organizational structure, grounded in a parish $<$ archpriesthood $<$ archdeaconry $<$ bishopric system, was established in the first half of the $12^{\text {th }}$ century. On a micro-level, however, the presence of this administrative hierarchy did not imply a parallel and immediate assertion of episcopal power over the local churches. The documents show the conflict between the participants that controlled both these churches and their income and the three main obstacles with which the Diocese of Calahorra had to deal in its growth: the monastic control of churches and rents, the repayment of loans to the nobility and the problems involved in ecclesiastical rent collection.

Keywords: high Middle Ages; diocese of Calahorra; noble powers; monasteries; proprietary church; parish.

\footnotetext{
* Este texto presenta algunas de las ideas desarrolladas en la tesis doctoral defendida por el autor en enero de 2016 en la Universidad del País Vasco (UPV/EHU) bajo el título La formación de la red parroquial en Álava y Treviño. Evidencias desde la arqueología (siglos XI-XIII). Ha sido realizado gracias a la ayuda para la especialización de personal investigador doctor 2017 del Vicerrectorado de Investigación de la UPV/EHU El autor desea agradecer enormemente a Álvaro Carvajal, Igor Santos, Rafael Varón y Javier Ordoño sus valiosas aportaciones para mejorar el texto.

Citation / Cómo citar este artículo: Alfaro Suescun, Egoitz (2020), Extensión y consolidación del poder episcopal sobre las iglesias de Álava durante los siglos XII-XIII: jerarquía administrativa y conflictividad local, "Anuario de Estudios Medievales" 50/1, pp. 3-30. https://doi.org/10.3989/aem.2020.50.1.01

Copyright: (C) 2020 CSIC. Este es un artículo de acceso abierto distribuido bajo los términos de la licencia de uso y distribución Creative Commons Reconocimiento 4.0 Internacional (CC BY 4.0).
} 


\section{SUMARIO}

1. Introducción.- 2. Dificultades y limitaciones de las fuentes escritas en el estudio.3. Análisis documental.- 3.1. Éxito a nivel macro: el establecimiento de una jerarquía diocesana durante la primera mitad del siglo XII.- 3.2. Obstáculos a nivel micro: las dificultades en la afirmación del poder episcopal en el mundo local durante los siglos XII y XIII.- 4. Conclusiones.- 5. Bibliografía citada.

\section{INTRODUCCIÓN}

El objetivo del presente trabajo consiste en delimitar los diversos momentos, velocidades y actores en liza del proceso de expansión diocesana sobre las iglesias y las dinámicas sociales del mundo local en el Territorio Histórico de Álava. Este proceso, que se desarrolló durante los siglos XIIXIII, fue el factor fundamental que hizo posible el paralelo encuadramiento plurisecular en parroquias. Así, la afirmación territorial, la uniformidad en la cura de almas o la jerarquización que asociamos a esta institución se explican porque la Iglesia, a través de los obispados, fue capaz de imponerse a los poderes nobiliarios, monásticos y comunitarios en el control de las iglesias. La identificación del control episcopal de las iglesias locales puede servir, por lo tanto, como indicador para evaluar el grado de implantación de la parroquia en el territorio.

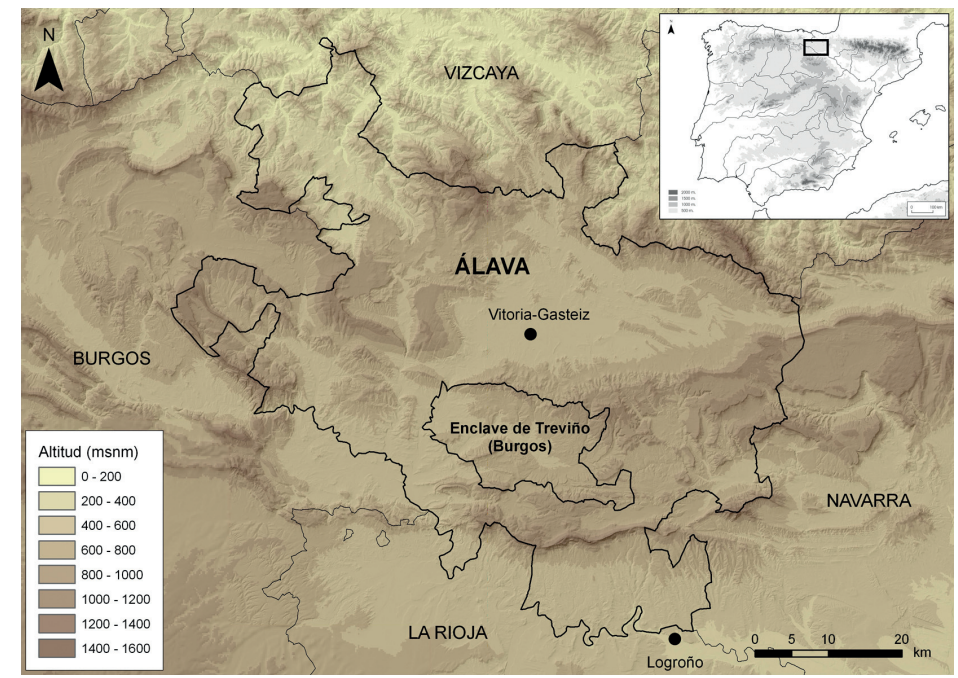

Fig. 1. Mapa contextualizando nuestro marco geográfico de estudio: el territorio histórico de Álava, en el centro-norte de la península ibérica. 
Este artículo matiza, concreta y desarrolla diversos aspectos publicados en trabajos sobre la temática y las coordenadas geográficas definidas. Son especialmente reseñables al respecto el texto de Carolina Carl sobre la ambivalente vinculación de Calahorra con las provincias de Vizcaya y Álava durante el episcopado de Rodrigo de Cascante ${ }^{1}$ (1147-1190), así como su libro en torno a la diócesis de Calahorra y sus relaciones con los reinos circundantes $^{2}$. Igualmente, cabe destacar la tesis doctoral de Tomas Sáenz de Haro sobre Calahorra y su entorno rural durante la Plena Edad Media ${ }^{3}$.

El territorio seleccionado, a pesar de su diversidad orográfica y climática, dispone de cierta homogeneidad a tener en cuenta para nuestro trabajo. Por un lado, son espacios que, aunque próximos a las diócesis altomedievales de Álava y Valpuesta, desde finales del siglo XI quedan lejos de los grandes centros episcopales (Burgos y Calahorra). Por otro, se trata de una región con un dominio casi total del poblamiento rural que no contó con núcleos urbanos de importancia hasta bien entrado el siglo XII o, incluso, el siglo XIII. Como es lógico, estos factores limitaron de forma notable la capacidad de las diócesis para extender su poder en la región.

Que este proceso de expansión se hiciera efectivo a partir del siglo XII parece responder a transformaciones que se hicieron tanto dentro como fuera de la administración eclesiástica ${ }^{4}$. Entre las primeras debemos poner el acento en la reforma gregoriana y la influencia que tuvo en la desaparición de las iglesias propias dominadas por laicos y monasterios. En esta línea, Susan Wood concluye que, aunque el fin de las iglesias privadas nunca estuviera en los programas del clero reformista, uno de los frentes principales sobre el que trabajaron fue la libertas ecclesiae (los otros fueron el fin de los vicios entre los clérigos y la centralización de la iglesia) $)^{5}$. Esto es, librarse de la posición desfavorable y de sometimiento que tenía la Iglesia en las estructuras feudales, principalmente en beneficio de los laicos ${ }^{6}$.

Los cambios exógenos se vinculan con el reordenamiento del mapa diocesano efectuado por la monarquía castellana en la segunda mitad del si-

${ }^{1}$ Carl 2008.

${ }^{2}$ Carl 2011.

${ }^{3}$ Sáenz de Haro 2012.

${ }^{4}$ Los métodos empleados en este proceso de expansión quedan fuera de los límites de este trabajo. Con todo, suponemos que no debieron diferir mucho de los seguidos en otros espacios peninsulares, como la diócesis de León: donaciones para la salvación del alma, con negociaciones que desembocaron generalmente en relaciones de patronazgo entre los propietarios y el obispo, y consagraciones de iglesias; Pérez 2017.

${ }^{5}$ Wood 2006, pp. 853-854, 864-865.

${ }^{6}$ Faci 1982, pp. 264-266; García de Cortázar 2012, pp. 257-261; Fernández Conde 1987, p. 43. 
glo XI. La coincidencia temporal, con algunas décadas de diferencia, entre el proceso de expansión por las iglesias rurales de Álava y Treviño y el nuevo control territorial por parte de Calahorra y Burgos no pudo ser casual. Aunque más alejadas, las nuevas sedes episcopales contaban ahora con el respaldo de entidades centrales consolidadas.

\section{DIFICULTADES Y LIMITACIONES DE LAS FUENTES ESCRITAS EN EL ESTUDIO}

Inferir a partir de la documentación escrita el grado de penetración de las administraciones diocesanas en el ámbito local de una determinada región es una labor problemática por varias razones. En primer lugar, porque las escrituras que se refieren a las iglesias de los obispados no son inventarios realizados ex professo, sino textos elaborados con otras finalidades: ventas, donaciones, pago de deudas o resoluciones para poner fin a un conflicto de propiedad. La imagen que ofrecen es, por tanto, circunstancial y fragmentaria.

A ello hay que añadir la diferente producción y conservación de los documentos según se trate de un obispado u otro, algo a tener en cuenta en Álava al estar bajo la influencia de cuatro diócesis diferentes en la Edad Media: Valpuesta y Álava antes de finales del siglo XI, Burgos y Calahorra después. De hecho, toda la documentación presentada en este trabajo corresponde a esta última, que dominaba la práctica totalidad del Territorio Histórico, salvo los valles más occidentales?

Asimismo, no debemos olvidar que los documentos son en sí mismos fuentes parciales y limitadas: fueron escritos por y para individuos de un nivel cultural, económico y social elevado (y, por tanto, con perspectivas vitales muy diferentes a las de la gran mayoría de la población), con una finalidad concreta (que pudo ser honesta o no) y para un momento y un territorio determinado (que podrá ser generalizable o no). Muchos de ellos, además, se han perdido o se han conservado deficientemente.

Otro impedimento en el uso de las fuentes escritas es la enorme variedad y confusión de la terminología eclesiástica en la documentación altomedieval y hasta los siglos X-XI. Los edificios de culto se denominan: ecclesiae, baselicae, cellae, decaniae o monasteria, sin que parezca que codifiquen un concepto concreto y definido, sino más bien una realidad difusa y con profundas variaciones regionales. Así, en ocasiones un mismo templo aparece mencionado como ecclesia y monasterium con una diferencia temporal dema-

\footnotetext{
${ }^{7}$ Consideramos oportuno reconocer a este respecto la trascendencia del trabajo de I. Rodríguez R. de Lama, de cuyas publicaciones se han obtenido la mayor parte de los documentos empleados en el texto.
} 
siado breve como para implicar cambios en su condición ${ }^{8}$. Esta variedad en la nomenclatura ha sido explicada a partir de modas regionales de los scriptoria monásticos o, simplemente, de confusiones terminológicas ${ }^{9}$, aunque también hay quien ha justificado esta homonimia entre ecclesia y monasterium en la existencia de parroquias-monasterio, esto es, pequeñas iglesias rurales con funciones parroquiales dirigidas por grupos monásticos de escasa entidad ${ }^{10}$. En esta misma línea J. Blair señala que la palabra latina monasterium (mynster en inglés antiguo) se utilizaba de manera amplia, para cubrir un gran número de fundaciones cuyo personal no se limitaba a un grupo restringido, habitualmente de nivel aristocrático, de monjes y monjas ${ }^{11}$.

Por otro lado, la nítida diferenciación entre clero regular y secular que asumimos a partir del siglo XII ${ }^{12}$ no parece existir durante los siglos anteriores. Así lo consideran diversos medievalistas. R. Sharpe advierte que debemos intentar evitar exagerar la distinción entre comunidades regulares y seculares $^{13}$, mientras que J.Á. García de Cortázar considera que antes de mediados del siglo XI resulta difícil distinguir, salvo casos concretos, el papel de multitud de monasterios con pequeñas y escasamente reguladas comunidades, de templos parroquiales o de otras unidades de convivencia y explotación del territorio $^{14}$. F.J. Fernández Conde, por su parte, irá algo más allá:

Quizá en este período -siglos VIII y X- resulte impropio o anacrónico hablar de clero regular y secular en cuanto realidades eclesiásticas contradistintas. Sólo más tarde, cuando se definan perfectamente los límites entre iglesia o monasterio propios, monasterio sub regula e "iglesia de aldea propiamente dicha" que hoy denominaríamos iglesia secular, podremos hablar, con propiedad, de un verdadero dualismo eclesiástico ${ }^{15}$.

${ }^{8}$ Loring 1987, p. 92.

${ }^{9}$ Peña 1995,p. 105.

${ }^{10}$ Loring 1987, pp. 90-92; Fernández Conde 2000, pp. 276-277.

${ }^{11}$ Blair 2005.

${ }^{12}$ Las despectivas palabras de Bernando de Claraval en su Apología a Guillermo de SaintThierry (ca. 1121-1124) reflejan bastante bien esta dicotomía: "Unos son los motivos de los obispos y otros los de los monjes (...), aquéllos debiéndose a los sabios y a los ignorantes excitan a la devoción del pueblo carnal con adornos materiales porque no pueden con los del espíritu. Pero nosotros que nos hemos separado del pueblo, que por Cristo hemos abandonado todo lo precioso y agradable del mundo, que hemos considerado como basura, para ganar a Cristo" Yarza 1997, pp. 219-221.

${ }^{13}$ Sharpe 1992, pp. 101-102.

${ }^{14}$ García de Cortázar 2008, p. 29.

${ }^{15}$ Fernández Conde 2000, p. 277. Esta indefinición alcanzó también las propias instituciones del clero secular. Así, por ejemplo, el cabildo de la catedral de Calahorra fue en origen, durante el siglo XI y los primeros años del siglo XII, una "comunidad capitular" impregnada por un destacable halo monástico. De hecho, los capitulares, que vivían y dormían juntos, son llamados 
Con todo, y siendo conscientes de estas limitaciones, consideramos que un análisis pormenorizado de los documentos plenomedievales que hagan referencia a las iglesias alavesas permitirá reconstruir, a grandes rasgos, el proceso de extensión de la administración eclesiástica sobre las iglesias rurales. Un proceso cuyo punto de partida se emplaza en el siglo XI cuando los obispados controlaban los templos aldeanos de iure pero no de facto, al estar en manos de nobles, monasterios o comunidades aldeanas. Su final, lo situamos en la Baja Edad Media, con todo el universo local insertado en la jerarquía parroquial y dominado por las diócesis. Pero, ¿qué ocurrió entre ambos momentos? ¿Cómo se desarrollaron estos cambios en nuestro ámbito territorial?

\section{ANÁLISIS DOCUMENTAL}

Los documentos que desde finales del siglo XI y hasta la segunda mitad del siglo XIII se refieren a la presencia de la administración diocesana en Álava revelan dos realidades desiguales en función de los niveles de análisis. Parece que su estructura organizativa básica, con base en la parroquia y con los arciprestazgos y arcedianatos como instituciones intermedias, se implanta con éxito pocas décadas después de los concilios reformadores. Desde la primera mitad del siglo XII existen referencias a territorios con personalidad propia e iglesias aldeanas donde el obispado de Calahorra percibía derechos eclesiásticos de diversa naturaleza.

Estos avances en materia administrativa y fiscal no implicaron, sin embargo, una afirmación paralela e inmediata del poder episcopal sobre las iglesias locales. Su propiedad y el control de sus rentas asociadas pertenecían a poderes que las habían monopolizado desde época altomedieval. Como es comprensible, las disposiciones conciliares no alteraron inmediatamente esta situación. Durante las décadas siguientes familias laicas y monasterios retuvieron en la práctica las iglesias y rentas que pertenecían, en teoría, al obispado. Esta conflictividad entre los diversos actores, evidente en la documentación analizada, se prolongó durante los siglos XII y XIII, y en algunos territorios incluso más allá.

fratres o monachi, la comunidad monasterio, conventus, communitas o claustrus y prior el cargo al frente de la misma. Sin embargo, toda esta vida en común y terminología monacal irá desapareciendo a lo largo del siglo XII, a raíz de su implicación en la administración de las propiedades diocesanas; Sáenz de Haro 2012, pp. 434-435, 437, 441, 477-520. 


\section{1. Éxito a nivel macro: el establecimiento de una jerarquía dio- cesana durante la primera mitad del siglo XII}

Las tres primeras escrituras que se traerán a colación muestran cómo el obispado de Calahorra fue implantando una administración jerárquica en Álava en las décadas posteriores a la Reforma Gregoriana. Permiten, por tanto, acompañar el proceso seguido en la conformación de dicha jerarquía, que fue detallada en la concordia del obispo Aznar, redactada a mediados del siglo XIII. Con estos tres documentos también se vislumbrará parte de la conflictividad que trataremos en el próximo apartado y que constata la necesidad de distinguir entre la voluntad del obispado en extender su poder sobre el territorio y la realidad con la que se encontró a nivel local.

Comenzaremos describiendo la situación preexistente. Antes de la Reforma Gregoriana y desde época altomedieval, fue patente la debilidad de los poderes episcopales en el control efectivo de los templos bajo su jurisdicción teórica. Las propias diócesis fueron entidades de escasa influencia transregional, ligadas a la presencia e intereses de una aristocracia local que adquirió cierta relevancia tras la desintegración del aparato de poder visigo$\mathrm{do}^{16}$.

Para el caso alavés debemos destacar los obispados de Valpuesta y Álava. El primero se documenta según E. Flórez y A.E. de Mañaricua desde comienzos del siglo IX ${ }^{17}$. I. Martín Viso, sin embargo, señala que su episcopologio sólo se puede reconstruir a partir de $911^{18}$, mientras que M. Carriedo lo retrasa a 929, con la primera mención del obispo Diego ${ }^{19}$.

En 1052 y tras fallecer el obispo Antonio la diócesis de Valpuesta fue agregada a la de Nájera por el rey de Pamplona García Sánchez III (10351054). Sin embargo, la anexión duró poco tiempo y antes de 1067 volvió a separarse, conservando su independencia hasta su definitiva incorporación a Burgos. Esto debió ocurrir entre 1084 y 1090, y muy probablemente entre los años 1086-1088 ${ }^{20}$.

${ }^{16}$ Martín Viso 1999,pp. 174, 178-179.

${ }^{17}$ Flórez 2007, pp. 26-27; De Mañaricua 1964, pp. 18-19. I. Santos, en un trabajo comparativo todavía inédito entre la diócesis de Valpuesta y la tirolesa de Sabiona, indica que, aunque fuera una escritura muy posterior, el documento "fundacional" de 804 refleja aspectos ciertos, como la dignidad episcopal de su fundador. Igualmente, plantea la posibilidad de que la mención en la Crónica Albeldense de Felemirus, obispo en Uxome, podría identificarse con un mitrado valpostano; Santos (en prensa). Una identificación ya sugerida con anterioridad; Martínez Díez 1984, p. 105; 2004, p. 17.

${ }^{18}$ Martín Viso 1999, p. 176.

${ }^{19}$ Carriedo 2002, pp. 71, 74, 97.

${ }^{20}$ Flórez 2007, pp. 133-140. 
De Mañaricua advierte ${ }^{21}$ que no se puede puntualizar cuándo comenzó a existir el obispado de Álava. Considera que con gran probabilidad existía ya a finales del siglo IX y ciertamente en la primera mitad del siglo $\mathrm{X}^{22}$. El primer mitrado conocido que se da el título de obispo de Álava es Munio en 98723. Se extinguiría apenas un siglo después, siendo el obispo Fortunio (? - ca. 1087) el último que ocupó la sede. Estuvo durante buena parte de su mandato, y hasta la muerte de Sancho Garcés IV en Peñalén (1054-1076), en la órbita de los reyes de Pamplona, siguiendo su corte y confirmando sus documentos ${ }^{24}$. Murió en una fecha indeterminada entre la segunda mitad de 1087 y comienzos de 1088, tras lo cual la diócesis fue absorbida por la de Nájera-Calahorra ${ }^{25}$.

Del obispo Fortunio se conserva un documento que refleja perfectamente la situación de debilidad de estas entidades episcopales. En el texto, fechado en 1085, el prelado de Álava renuncia a favor de San Juan de la Peña a los derechos que sobre tercias y cuartas decimales y otras oblaciones tuviera sobre las iglesias que poseía este monasterio en su territorio diocesano ${ }^{26}$.

Con todo, y tal y como se ha avanzado, a finales del siglo XI se reestructuró el mapa diocesano del norte peninsular, eliminando los antiguos obispados de Álava y Valpuesta e integrándolos en las diócesis de Calahorra y Burgos respectivamente. El nuevo aparato político central de los reinos cristianos, más homogéneo que las pequeñas construcciones sociopolíticas altomedievales, demandaba una organización episcopal a su medida ${ }^{27}$.

Esta concentración diocesana no supuso, sin embargo, un inmediato vuelco de la situación anterior. Los obispados, aunque más alejados y con más dificultades para imponer su autoridad, trataron de imponer las prerrogativas

${ }^{21}$ Y después de analizar las opiniones de estudiosos del tema como G. de Argáiz (siglo XVII), J.J. de Landazuri (1730-1805), R. de Floranes (1743-1801), B. Ibáñez de Echavarri (mediados siglo XVIII), Manuel Risco (1735-1801), J. A. Llorente (1756-1823), Z. García Villada (1879-1936), L. Serrano (1879-1944), J. Pérez de Urbel (1875-1979) y A. Ubieto Arteta (1923-1990); De Mañaricua 1964, pp. 32-41.

${ }^{22}$ Plantea sus dudas sobre los primeros obispos de Álava: Bívere (876?), Álvaro (881-888?) y Munio (937 y 956). Parece que ejercieron jurisdicción en tierras alavesas que no pertenecieron nunca a Valpuesta, pero no puede afirmar con seguridad que los dos primeros no ocupasen la sede valpostana; De Mañaricua 1964, p. 40. J.J. Larrea, defiende la presencia de un obispo en Álava, ubicado en la llanada, para las primeras décadas del siglo X, en tiempos de los condes de la familia Vela. Se basa para ello en la Crónica Albeldense y en el epitafio de 928, hallado como sillar reutilizado en la iglesia de San Andrés de Bolívar, en las afueras de Vitoria-Gasteiz; Larrea 2007,pp. 74-75.

${ }^{23}$ De Mañaricua 1964, pp. 40-41; Martínez Díez 1984, p. 119.

${ }^{24}$ A pesar de esta cercanía a la monarquía pamplonesa hasta 1076, J.J. Larrea considera que la sede de Armentia nunca apareció más realzada en su papel de centro de poder como en los años bajo la influencia del rey Alfonso VI; Larrea 2007, p. 112.

${ }^{25}$ De Mañaricua 1964, pp. 124-126, 141; Risco 2009, pp. 243-244.

${ }^{26}$ Ibidem, p. 139.

${ }^{27}$ Martín Viso 1999, pp. 183-186. 
de la Reforma Gregoriana, con éxito relativo, como refleja el documento del obispo Sancho de Grañón.

Lo primero que conviene tener en cuenta de dicho texto es que es sospechoso: hoy en día se desconoce su paradero ${ }^{28}$ y, según I. Rodríguez R. de Lama, tiene un estilo y un lenguaje que parece orientarnos a fechas más tardías. Parece que se trata, por tanto, de la redacción tardía de un acontecimiento que probablemente sí que tuvo lugar ${ }^{29}$.

El texto resulta de interés porque narra las hostilidades entre el obispo Sancho de Grañón (1109-1116) y los nobles alaveses a causa de las iglesias de este territorio. Se presupone que pasan varios años entre los primeros acontecimientos referidos y el acuerdo plasmado en la reunión final celebrada en Estíbaliz entre el obispo Sancho y los barones, pero no hay referencias al respecto ${ }^{30}$.

Al parecer, a causa de diversos excesos y atropellos en la gestión de las iglesias privadas alavesas, cometidos tanto por los nobles, los clérigos y el pueblo, el obispo decidió excomulgar a los habitantes de Álava hasta que reconocieran la culpa, aceptaran la penitencia y juraran que no iban a cometer de nuevo dichos actos. Y ello hicieron:

Los señores juraron al obispo y a Dios que no obligarían a sus siervos a que entregasen diezmos y donativos eclesiásticos más que a aquella iglesia en la que a lo largo de todo el año asistieran a los rezos, las misas y en las que recibieran los demás servicios de Dios conforme a las disposiciones del obispo y su arcediano (...) Los villanos, por su parte, juraron que ofrecerían y donarían fielmente sus diezmos, primicias y ofrendas a Dios y a su Santa Iglesia como más arriba está escrito, sin fraude ni mala disposición. Los clérigos, por su parte, juraron que mantendrían íntegros sus altares y que servirían adecuada y pulcramente a Dios y a su iglesia y que ninguno se entrometería en la iglesia de otro, y que, como es justo y apropiado, entregarían al obispo, su señor, la cuarta de cada iglesia.

Hubo, sin embargo, una contrapartida que el obispo aceptó a regañadientes (obligado, que no de propia voluntad) por la que los nobles alaveses

\footnotetext{
${ }^{28}$ La única transcripción conservada de este texto es la que realizó J.A. Llorente para su obra de 1808: Noticias históricas de las tres provincias vascongadas: Álava, Guipúzcoa y Vizcaya; Llorente 1808, pp. 7-10. Como el pergamino en el que se encontraba fue sustraído o se perdió en algún momento posterior, todas sus publicaciones recientes se limitan a reproducir la versión del erudito decimonónico.

${ }^{29}$ Rodríguez R. de Lama 1992, p. 114.

${ }^{30}$ El pergamino carece de fecha porque está cortado y le falta el fin de la escritura; Llorente 1808 , p. 9.
} 
consiguieron que asignase pueblos a las iglesias privadas para que sus habitantes pagaran en ellas los diezmos eclesiásticos.

En cualquier caso, los barones acabaron rompiendo el juramento y fueron convocados a Estíbaliz a una reunión con el obispo. Delante de Sancho, volvieron a reconocer sus culpas y acordaron que los pueblos que sirvieran a ciertas iglesias por imposición quedasen libres. El mitrado accedió, por otra parte, a entregar a los señores los ingresos derivados de las multas por sacrificio y fornicación clerical.

Destacan del texto tres cuestiones. Primero, la territorialidad que acompañaba a estas iglesias parece flexible y difusa. No existía la correspondencia iglesia/aldea, por lo que suponemos que muchos núcleos no dispondrían de templos y sus habitantes debían acudir a alguno del entorno y pagar las rentas eclesiásticas a sus dueños. Del mismo modo, y tal como está constatado por el registro documental y arqueológico, algunas poblaciones contarían con más de un templo en su seno ${ }^{31}$. Esta indefinición territorial acabó generando múltiples conflictos, ya que cada barón propietario trataba de hacer pagar en sus iglesias a la mayor cantidad de campesinos, tuvieran derecho a ello o no.

Segundo, aunque los diferentes actores en liza mencionados en el documento asumen la autoridad del obispo en la jurisdicción de las iglesias alavesas, queda patente su reticencia a hacer cumplir los dictámenes emanados de la diócesis. Tras una primera situación de desobediencia previa, nobles, clérigos y campesinos vuelven a incumplir el acuerdo alcanzado con el obispo. Desconocemos además si el propio pacto firmado en Estíbaliz volvió a ser violado más adelante. El texto refleja, por tanto, la conflictividad política

\footnotetext{
${ }^{31}$ Documentalmente se identifican en Álava los casos de Estavillo, Abezia y Egileor. En el primero una donación a San Vicente de Acosta de 871 menciona las iglesias de Santa Engracia y San Martín en Estavillo ("ecclesias Sancta Gratia et Sancti Martini, in villa Stabellu") Becerro Galicano Digital (doc. 220) (www.ehu.eus/galicano/id220 [consulta: 06/02/2018]). Que el documento sea espurio, elaborado en una fecha mucho más tardía, no lo invalida como prueba de la existencia de varias iglesias dentro de una misma población en cronologías anteriores a la extensión parroquial; Martínez Díez 1998,p. 23. En Abezia otra donación de 937 al monasterio de San Esteban de Salcedo se refiere a los templos de San Clemente, San Martín y San Salvador ("Sancti Clementi et Sancti Martini et Sancti Salvatoris, in loco qui dicitur Abalca") Becerro Galicano Digital (doc. 525) (www.ehu.eus/galicano/id525 [consulta: 06/02/2018]). En el caso de Egileor, una tercera donación de 1076, en esta ocasión a San Millán de la Cogolla, cita las iglesias de San [Pedro], San Emiliano y Santa María ("Et media de illa ecclesia Sancti, intus villa, cum casa ad eam tenentem. Et media de ecclesia Sancti Emiliani, sita de super villa. Et media de ecclesia Sancta Maria, deorsum villa". Becerro Galicano Digital (doc. 561) (www. ehu.eus/galicano/id561 [consulta: 06/02/2018]). Este último caso está documentado además por medio de prospecciones arqueológicas; Quirós 2011,p. 202. Igualmente, E. Peña señaló que la documentación del siglo IX y primer cuarto del siglo X mencionaba más iglesias/monasterios que aldeas en territorios situados al norte de Castilla, entre ellos la Álava nuclear; Peña 1995 , p. 127.
} 
que surge en este momento en torno a las iglesias locales y que se explica por la tenacidad con la que sus propietarios defendieron la independencia de sus posesiones y prerrogativas frente al obispado.

Tercero, pese a que se haga referencia a la figura del $\operatorname{arcediano}^{32}$, lo que sugiere la presencia de una mínima jerarquía administrativa, los conflictos y acuerdos incumplidos que recoge el propio documento indican que su plasmación efectiva sobre las iglesias y los diversos poderes que operaban sobre el territorio era restringida.

Hay otras dos escrituras posteriores de la primera mitad del siglo XII que constatan un mayor desarrollo de la administración diocesana respecto a la limitada coyuntura descrita en el documento de Sancho de Grañón. En ellos se confirma la implantación de una jerarquía administrativa dirigida desde Calahorra, basada en el esquema parroquia $<$ arciprestazgo $<$ arcedianato $<$ obispado. Este cuadro organizativo fue expuesto con gran detalle en la célebre concordia del obispo Aznar, redactada un siglo más tarde, en 1257.

Es necesario tener en cuenta que de esta concordia se han conservado dos versiones con algunas diferencias entre ellas, la mayoría de ellas sin importancia ${ }^{33}$ pero con otras de mayor calado (infra). En el texto se reparten las rentas de la diócesis de Calahorra entre el obispo, Jerónimo Aznar (12381262), y los clérigos del cabildo catedralicio, con la aprobación del cardenal Gil Torres, delegado del papa. Para ello se efectúa un listado exhaustivo de las iglesias que producen estas rentas, agrupadas en arciprestazgos y éstos, a su vez, en arcedianatos.

El espacio que ocupa actualmente el Territorio Histórico de Álava estaba repartido en tres arcedianatos: Álava, Nájera y Berberiego; y quince arciprestazgos: Eguilaz (en el que se mencionan 83 iglesias aldeanas), Gamboa (15), Cigoitia (24), Vitoria (63), Zuibarrutia (15), Cuartango (35), Orduña (21, 17 en Álava), Ribera (38), Treviño (80) y Ayala ${ }^{34}$ en Álava; Miranda (7 en Álava) y Laguardia (no incluyen ninguna mención) en Nájera; Viana (8), Bernedo (21), Arana y Arraya (19) ${ }^{35}$ en Berberiego.

\footnotetext{
${ }^{32}$ Se entiende que de Álava y que tendría bajo su control el territorio de la antigua diócesis homónima. Los arcedianatos surgieron, como circunscripciones en las que se dividía la diócesis en la segunda mitad del siglo XI o a inicios del siglo XII, cuando los obispos determinaron su número y límites geográficos; Fernández Conde 1982, p. 437.

${ }^{33}$ Rodríguez R. de Lama 1989, p. 233, notas al pie n. ${ }^{\circ} 1,9,11$.

${ }^{34}$ No se menciona ninguna aldea; sólo un vago Bizcaya y una casa en Uciorça; Rodríguez R. de Lama 1989, p. 221.

${ }^{35}$ En origen en este arciprestazgo se hacía referencia únicamente al monasterio de Santa Pía, hoy desaparecido y que se hallaba en los alrededores de Cicujano. Las 19 menciones referidas aquí sólo aparecen en una de las dos versiones y "están puestas ciertamente de mano más tardía”, por lo que habrá que considerarlas con cautela; Rodríguez R. de Lama 1989, p. 233, nota al pie n..$^{\circ} 15$.
} 
El hecho de que la distribución de las iglesias entre la mesa episcopal y capitular no sea equitativa (74,4\% para el obispo y $25,6 \%$ para el cabildo $\left.{ }^{36}\right)$ y que haya una serie de rentas que hasta entonces había pertenecido al cabildo pero que vuelven al obispo sugiere a T. Sáenz de Haro ciertas preferencias geográficas por parte de los capitulares. Según este autor el cabildo habría tratado de alejarse de templos septentrionales o insertos en el reino de Navarra (como las del arcedianato de Berberiego) por la dificultad que suponía la recaudación diezmal. Estas preferencias parecen confirmarse con una permuta de 1268 en la que el cabildo devuelve al obispo Vivián (1263-1273) 18 de las cuartas episcopales que poseía en Álava ${ }^{37}$.

En la concordia hay importantes ausencias. Así, de los 31 núcleos actuales (los 11 restantes quedaron despoblados) referidos en los documentos de 1135 y 1156, y que suponemos continuaban bajo autoridad episcopal, únicamente dos (Miñano y Ullibarri-Jauregui) aparecen repetidos en la concordia de 1257. Como resulta improbable que todas estas iglesias pasaran a otras manos en el intervalo de tiempo que transcurre entre los documentos y la concordia $^{38}$, podemos suponer que no son mencionados en esta última porque dichas iglesias pertenecían ya al cabildo catedralicio de Calahorra (documento de 1156) o al arcediano de Álava (documento de 1135).

\footnotetext{
${ }^{36}$ De las iglesias del arcedianato de Álava el obispo recibe 282 (T. Sáenz de Haro cuenta el arciprestazgo de Ayala como una, al no enumerarse sus templos) y el cabildo 97 (también cuenta el arciprestazgo de Léniz como una iglesia más). Lo mismo ocurre en el arcedianato de Berberiego: 45 para el obispo y 29 para el cabildo. Sin embargo, en los arcedianatos de Nájera, Calahorra y Cameros la situación es mucho más equilibrada; Sáenz de Haro 2012, p. 725.

${ }^{37}$ Resulta llamativo que casi todas (16) correspondan al documento de 1156 (infra) y sólo Azilu a la concordia de 1257: Betolaza, Ziriano, Nafarrate, Azilu (Ancilu), Luko, Goiain (Goyahyn), Arroiabe, Ullivarri-Gamboa, Munain, San Román de San Millán, Ordoñana, Mezkia, Arzubiaga y los despoblados de Arzamendi, Lehete, Paternina, Berececa y Bagoeta? (Barochata) (Rodríguez R. de Lama, 1989, 269-270) a cambio de las tercias de Navarrete, núcleo cercano a Logroño, más rentable y cercano a sus otras propiedades inmuebles; Sáenz de Haro 2012, pp. 724-726, 734, 748 .

${ }^{38}$ Con la salvedad de Vitoria-Gasteiz. Aunque la iglesia de Gasteiz es mencionada en el documento de 1135 entre las cuartas episcopales que se entregan a Armentia parece que, tras su transformación en villa el año 1181, el rey Sancho VI de Navarra retuvo para sí el control de las iglesias de la ciudad. El patronato real se mantuvo tras la conquista castellana de 1200 como demuestran dos misivas que el rey Alfonso X envía al obispo Aznar en 1255 y 1257 y la propia confirmación, ese mismo año, por parte de este último del ius patronatus en todas las iglesias vitorianas para dicho rey y sus sucesores; González Mínguez 1977,p. 458. Ello explicaría la ausencia de iglesias de esta ciudad en la concordia de 1257 a pesar de ser cabeza de arciprestazgo y, quizá, la de otras villas destacadas como Treviño o Laguardia.
} 


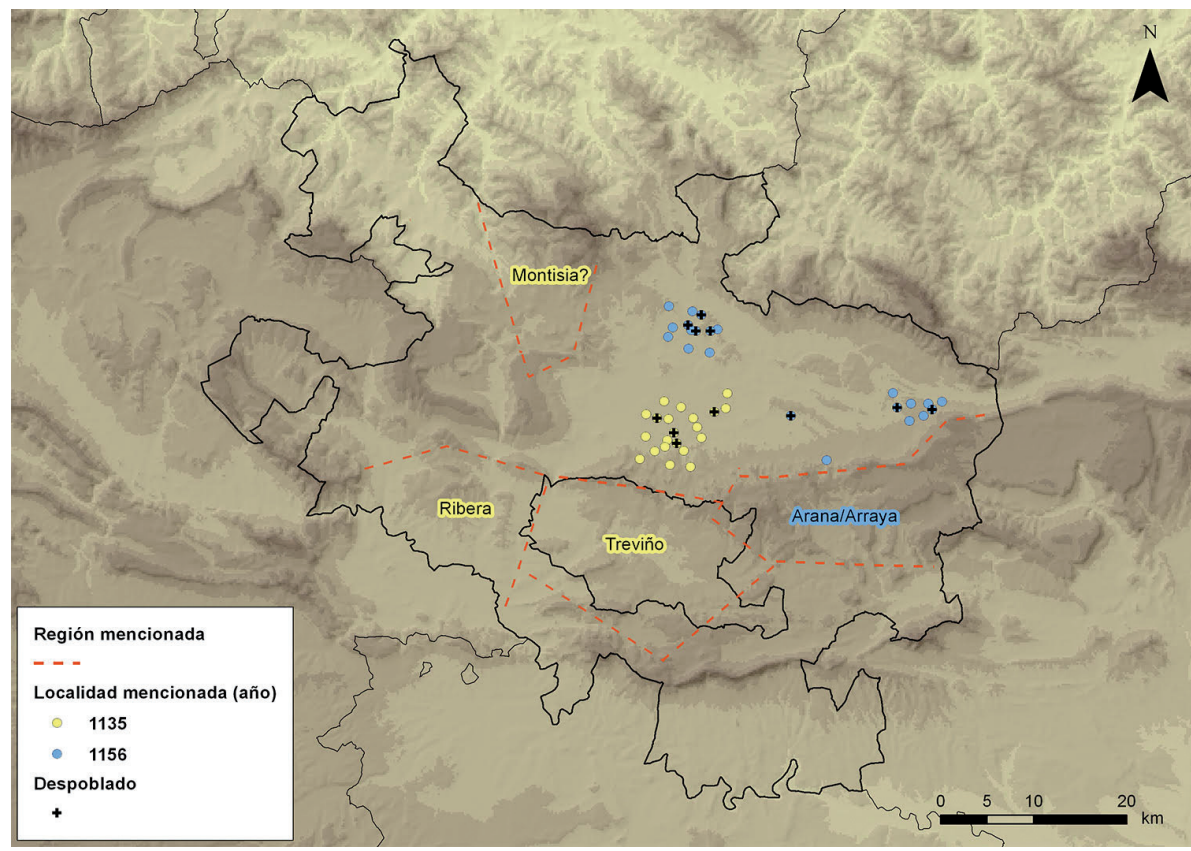

Fig. 2. Mapa con las iglesias alavesas mencionadas en la concordia de 1257 indicando el arciprestazgo y el arcedianato al que pertenecían ${ }^{39}$.

No obstante, y como se ha comentado más arriba, parece que la jerarquía administrativa de la diócesis calagurritana en Álava es bastante anterior a la concordia de 1257. Así, en un documento fechado en 1135 , el obispo de Calahorra Sancho de Funes (1118-1146), le entrega a Pedro, arcediano de Álava, los siguientes beneficios: la iglesia de San Andrés de Armentia con sus heredades y frutos de ese año; las cuartas episcopales de veinte templos del entorno ${ }^{40}$ para la subsistencia de los clérigos que viven en la iglesia; la mitad de las cuartas de $\operatorname{Iueta}^{41}$ y el cuarto de vino de Ripera $^{42}$ y

${ }^{39}$ El emplazamiento de los despoblados es aproximado y está fundamentado en los diversos trabajos consultados al respecto (López de Guereñu 1989; González de Viñaspre 2007; González de Viñaspre, Uribarrena 2012; Pozuelo 2013). Se han obviado 11 casos, aquellos cuyas referencias eran demasiado vagas como para arriesgar una ubicación (Tres Quintanas, Eztenueran, Urdascay, Echauarri, Vayas, Caycedo de Suso, Uxeminiuilla, Solas, Chavarri, Doncis y Colantes).

${ }^{40}$ Se trata de los templos de Berrostegieta, Lasarte, Gardelegi, Aretxabaleta (Harizaballeta), Gasteiz, Ali (Ehari), Arriaga, Betoño, Elorriaga, Arkaia, Mendiola, Castillo (Gaztelu), Monasterioguren (Monasterium Gurena), Otazu, Ilarratza, Junguitu y de los hoy despoblados Petriquiz, Adurza, Abendaño y Olarizu.

${ }^{41}$ Cuenca del río Ayuda, denominación empleada para referirse a Treviño.

${ }^{42}$ La región de Ribera, cuenca baja del río Bayas, mencionada como arciprestazgo en 1257. 
Montisia $^{43}$ y la mitad de los frutos de leche y queso de las vacas que están en San Andrés. El mitrado, asimismo, determina el número de clérigos que debía disponer el arcediano en dicha iglesia: diez, dos sacerdotes y ocho clérigos mayores $^{44}$.

El texto refleja dos cuestiones de cierta importancia. Por un lado, que en 1135 la diócesis de Calahorra recaudaba censos eclesiásticos en diversas zonas de Álava, al menos en la llanada y las cuencas del río Ayuda y Bayas (arciprestazgos de Vitoria, Eguilaz, Treviño y Ribera en 1257). Estos dos últimos además se aluden mediante términos concretos, indicando que ya disponían de personalidad propia.

Por otro, que el obispado disponía en Álava para ese momento de una básica jerarquía administrativa. Ello no sólo es evidente porque el propio documento sirva para reforzar la figura del arcediano de Álava (cargo mencionado ya en el texto de Sancho de Grañón, como se ha indicado), sino por las referencias a espacios determinados que se ajustan a los arciprestazgos. Un término que, en cualquier caso, no se llega a emplear.

De otro documento redactado dos décadas más tarde, en 1156, se infiere también la implantación de dicha jerarquía. En este, el obispo de Calahorra, Rodrigo de Cascante, asigna a su cabildo catedralicio las tercias y cuartas decimales de varias aldeas riojanas y alavesas. En lo que respecta a Álava se mencionan las cuartas de 22 núcleos ${ }^{45}$, situados todos en la llanada, y, de forma general, de la región de Arana y Arraya ${ }^{46}$. Se alude además a los arcedianos del obispo (archidiaconis nostris), en plural ${ }^{47}$.

Si hacemos balance de los documentos de 1135 y 1156 es posible concluir que a mediados del siglo XII la diócesis calagurritana percibía cuartas episcopales en cinco de los nueve arciprestazgos del arcedianato de Álava referidos en 1257. No hay menciones explícitas, sin embargo, a la figura del arciprestazgo. Se alude a Treviño, Ribera, quizá Zuibarrutia (Montisia) y sin nombrarlos, aunque refiriéndose a buena parte de sus iglesias, a Vitoria y Eguilaz. Cabría preguntarse por qué no se emplea todavía el término "arciprestazgo" cuando se hace referencia a sus espacios concretos y cuando se

\footnotetext{
${ }^{43}$ Dudamos respecto al significado de este término. Podría referirse a la cuenca alta del río Bayas, que arranca de las estribaciones montañosas del Gorbea y que coincidiría con el arciprestazgo de Zuibarrutia en 1257, o a alguno de los espacios montañosos del norte de Álava.

${ }^{44}$ Rodríguez R. de Lama 1992, pp. 178-179.

${ }^{45}$ En concreto: Ziriano, Betolaza, Nafarrate, Goiain, Arroiabe (Roiaue), Luko, UllívarriGamboa, San Román de San Millán, Eguílaz, Vicuña, Munain, Ordoñana, Mezkia, Miñano (¿Mayor o Menor?), Ullíbarri-Jauregi? (Hurriuarri) y las hoy despobladas Anguellu, Bagoeta, Arzamendi, Lehete, Ayala, Berececa y Paternina.

${ }^{46}$ Harana y Harrahia en el texto.

${ }^{47}$ Rodríguez R. de Lama 1992, pp. 275-276.
} 
menciona la entidad inmediatamente superior, el arcedianato. De hecho, no se menciona explícitamente un arciprestazgo hasta bastantes después, en un documento de 1229 (infra $)^{48}$. ¿Podría indicarnos, quizá, una implantación más tardía de dicha institución?

Estos cinco arciprestazgos, al que habría que añadir Arana-Arraya, del arcedianato de Berberiego, representan el núcleo central del territorio alavés: desde la frontera oriental con el reino de Navarra hasta el rio Bayas y desde las estribaciones montañosas del norte al sur de la cuenca del río Ayuda. Desconocemos si la ausencia de referencias a los cuatro arciprestazgos restantes de 1257 (Cigoitia, Cuartango, Gamboa y Orduña) es, por tanto, fruto de una eventual falta de control episcopal sobre las regiones más periféricas de la Álava nuclear, o si se debe, más bien, a la casualidad, con lo que la diócesis habría logrado afirmarse en ellas de forma efectiva, aunque sin dejar huella documental. La evidencia analizada hace que nos inclinemos hacia la segunda opción.

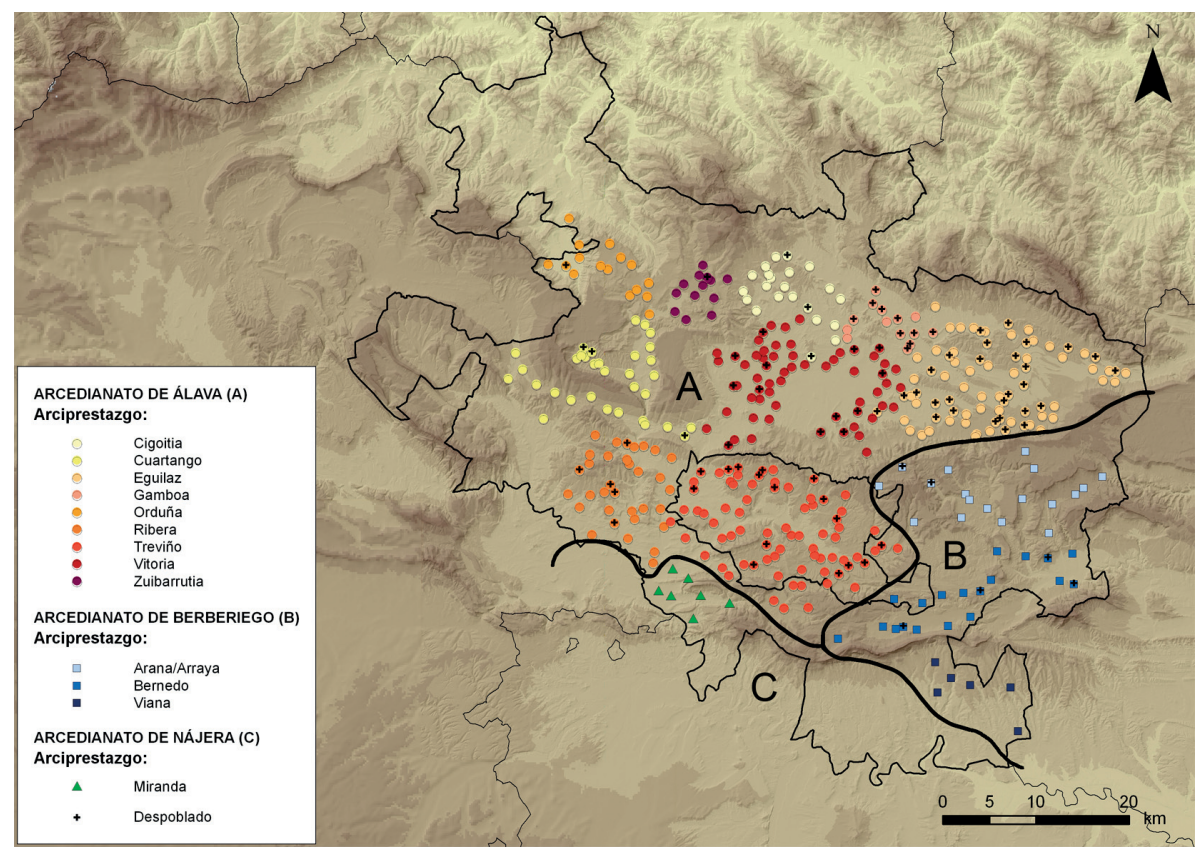

Fig. 3. Mapa con las iglesias y regiones de Álava mencionados en los documentos de 1135 y $1156^{49}$.

${ }^{48}$ Rodríguez R. de Lama 1989, p. 92.

${ }^{49}$ Las fronteras de las regiones se han dibujado a partir de las de los arciprestazgos de 1257 La localización de algunos despoblados es aproximada y se fundamenta en los trabajos citados (véase Fig. 2). 


\subsection{Obstáculos a nivel micro: las dificultades en la afirmación del poder episcopal en el mundo local durante los siglos XII y XIII}

$\mathrm{Al}$ descender a una escala micro, el éxito aparente alcanzado por el obispo de Calahorra en Álava con la implantación de una jerarquía diocesana y el cobro efectivo de censos queda bastante matizado. La documentación posterior, que abarca la segunda mitad del siglo XII y el siglo XIII, muestra que muchas iglesias locales seguían en manos de poderes ajenos a la diócesis. Familias nobles, monasterios y, quizá, comunidades aldeanas con los que fue necesario enfrentarse y, con el tiempo, negociar.

De los documentos de estas dos centurias se infieren tres grandes obstáculos con los que tendrá que lidiar la diócesis en el camino hacia la afirmación de su poder a escala local: el control de iglesias por parte de monasterios; la devolución de préstamos a la nobleza cediendo rentas eclesiásticas; y los problemas en el cobro de estas. Los tres reflejan un dominio parcial del poder de Calahorra en Álava, así como una capacidad relativa para percibir sus censos.

\subsubsection{El control monasterial de iglesias y censos}

En relación al primero de estos obstáculos, la persistencia del poder monasterial sobre las iglesias alavesas, se hará alusión a tres textos. El primero de ellos es un acuerdo de 1163 en el que el obispo de Calahorra, Rodrigo de Cascante, renuncia a cobrar las tercias y las cenas de una veintena de iglesias de la diócesis en beneficio del monasterio de San Millán de la Cogolla, para acabar con el largo conflicto que mantenían ambas instituciones. Como contrapartida el obispo se quedaría únicamente con las tercias de Madrid de los Trillos $^{50}$ y Camprovín, en La Rioja.

Si bien es cierto que casi todas las iglesias referidas están situadas en el entorno del monasterio de San Millán, en tierras riojanas, se incluyen también dos ubicadas al norte del Ebro, en Treviño: Albaina y Marauri ${ }^{51}$. Pese a esta parca mención, el documento permite inferir que el obispado distaba todavía de controlar plenamente las iglesias alavesas y sus censos a mediados de siglo XII. Una situación que no parece ser algo excepcional de este territorio, como muestran el resto de los templos riojanos citados en el texto.

${ }^{50}$ Madriz en el texto.

${ }^{51}$ Alviano y Maurucuri en el texto. 
El segundo documento es una misiva fechada en torno a 1193 del obispo de Calahorra García Fernández (1190-1194) al papa porque el monasterio cluniacense de Santa María de Nájera impedía la percepción de los derechos episcopales en algunas de las iglesias de la diócesis. Entre estos derechos se aluden específicamente que los sacerdotes recibieran la institución canónica de los obispos y que se percibiesen los diezmos de todos aquellos feligreses que recibían los sacramentos en las parroquias ${ }^{52}$. La mayoría de las iglesias referidas están ubicadas en La Rioja, aunque también se mencionan cuatro en Navarra y cinco en Álava: Moreda, Urturi, Angostina, Santa María de Estíbaliz ${ }^{53}$ y Leza ${ }^{54}$.

Se observa, de nuevo, cómo en la pugna del obispado con los grandes monasterios de la diócesis el territorio de Álava tuvo una trascendencia tangencial, siendo la gran parte de las iglesias en liza riojanas y próximas a los cenobios. En cualquier caso, y como en la escritura anterior, estas referencias permiten matizar el dominio episcopal sobre las iglesias alavesas.

Por otro lado, estos conflictos entre obispados y monasterios por el control de las iglesias locales y sus censos a partir de la Reforma Gregoriana no fueron ninguna excepción ${ }^{55}$. En Navarra, por mencionar un ejemplo próximo, el monasterio de Leire mantuvo numerosos enfrentamientos y pleitos con el obispo de Pamplona entre 1139 y 1208 por cuestiones tanto jurisdiccionales como económicas, de los que la diócesis salió triunfante. Las propias luchas entre los referidos monasterios de San Millán y Santa María de Nájera fueron muy desiguales: mientras que el primero consiguió, gracias a una acertada estrategia frente a Calahorra, mantener buena parte de los diezmos disputados durante el siglo XII, el segundo se enfrentó durante casi un siglo con el obispado (entre 1143 y 1224) para acabar sufriendo sucesivas derrotas $^{56}$.

${ }^{52}$ Núñez de Cepeda 1931, pp. 534-536.

${ }^{53}$ Hurtuguri, Angustina y Stiualez en el texto.

${ }^{54}$ Rodríguez R. de Lama 1979, pp. 118-119.

${ }^{55}$ Para el caso concreto de los conflictos entre monasterios de Cluny y obispados desde mediados del siglo XII hasta mediados del siglo XIII: Reglero 2008, pp. 355-396. Sitúa el reparto de diezmos como el centro de estas disputas y, además del caso de Santa María de Nájera y Calahorra, menciona otros en los obispados de Astorga, Coimbra, Burgos, Zamora, Salamanca, Palencia y León; ibidem, pp. 370-379.

${ }^{56}$ Tanto J. Á. García de Cortázar como L. J. Fortún ofrecen una periodización similar en el enfrentamiento entre monasterios y obispados por el control de las iglesias, y especialmente sus censos. El primero propone cinco fases en el control diezmal para el caso concreto del monasterio de San Millán de la Cogolla. En la primera fase (mediados del siglo X-1075) el cenobio pasó a controlar la percepción de diezmos y tercias de las iglesias que pasaban a su dominio. Durante la segunda (1075-1140) comenzaron los enfrentamientos con la Iglesia secular con motivo de los procesos reformistas. San Millán reaccionó elaborando documentos falsos y pleiteando, con lo que consiguió la cesión de parroquias concretas por parte de la diócesis de Calahorra. 
De hecho, resulta ilustrativo de estas dinámicas que las dos iglesias alavesas referidas en el documento del 1163 y tres de las cinco de $c a .1193$ aparezcan en la concordia de 1257 como parte del patrimonio diocesano ${ }^{57}$.

Aunque el tercer y último documento, fechado en 1240, aluda también a un monasterio, no parece tratarse de uno de la entidad de los anteriores. La información que aporta parece sugerir que se trataba más bien de una posesión de carácter familiar probablemente controlada por laicos. Así y según nos indica el texto, Iñigo de Mendoza dona al obispo su parte del monasterio de Santa María de Pangua, con sus heredades y pertenencias, y a su cabildo catedralicio su porción de las cuartas diezmales en las iglesias alavesas de Pangua, San Esteban de Treviño, Añastro, Faido, Muergas, Lacervilla ${ }^{58}$, Estavillo, Burgueta y Amifollas si se llegase a poblar ${ }^{59}$.

Del documento se deduce que hasta la donación de Iñigo de Mendoza a Calahorra las cuartas referidas, o al menos parte de ellas, estaban bajo control del monasterio de Pangua. Queda patente, por lo tanto, que a mediados del siglo XIII todavía había en territorio alavés iglesias y censos eclesiásticos en manos de laicos y monasterios.

\subsubsection{Devolución de préstamos a la nobleza}

El segundo de los obstáculos, la cesión temporal de derechos y posesiones del obispado a nobles para la devolución de préstamos, tuvo un carácter más puntual pero deja entrever la debilidad de la diócesis, que transigía en ceder sus beneficios a laicos a cambio de dinero. Para ámbito alavés se hará referencia a dos documentos.

El primero de ellos es un convenio de 1173 entre Gonzalo de Hornillos y el obispo de Calahorra Rodrigo de Cascante. El primero se comprometía a devolver las cuartas episcopales de las aldeas alavesas que tenía como fianza de los 500 morabetinos prestados al obispo; a saber: Atauri y la mitad de

Durante la tercera (1140-1175) el monasterio se benefició de esta doble política, mientras que en la cuarta (1175-1225) se redujo el número de enfrentamientos. En la quinta y última fase (desde 1225) volverán con virulencia los enfrentamientos con el obispado por el control de los diezmos; García de Cortázar 1988, pp. 115-117. L. J. Fortún, por su parte, diferencia sólo dos fases en la pugna que surgió en el siglo XII entre monasterios y obispos en la península ibérica: una primera, entre 1140 y la muerte de Alejandro III (1181), muy favorable a los cenobios y una posterior, que se extendió hasta las primeras décadas del siglo XIII, en la que los obispos obtuvieron importantes victorias; Fortún 2001, pp. 239-241.

${ }^{57}$ Del documento de ca. 1193: Moreda, Urturi y Angostina; Rodríguez R. de Lama 1989, pp. 222, 232.

${ }^{58}$ Lizerevilla en el texto.

${ }^{59}$ Rodríguez R. de Lama 1989, pp. 135-137. 
Letona y Apodaka. El mitrado, por su parte, le entregaba las llaves de la casa episcopal de Armentia hasta su muerte, le devolvía las cuartas cedidas, le concedía otras no especificadas en Álava para que rescatara cuartas empeñadas a otros prestamistas, le permitía retener las minucias de las cuartas cedidas y le asignaba un sueldo anual de seis modios de trigo ${ }^{60}$.

En la segunda escritura, de 1229, el obispo de Calahorra, Juan Pérez (1220-1236), para amortizar los 3300 morabetinos que quedaban de una deuda de 4000, entrega a Lope Díaz de Haro las cuartas episcopales de más allá del Ebro ${ }^{61}$, a excepción de la casa de Armentia y sus pertenencias, la mitad del arciprestazgo de Treviño ${ }^{62}$ y las cuartas de Eguilaz, salvo algunos cuartos que estaban ya empeñados ${ }^{63}$, Vitoria ${ }^{64}$, Cigoitia ${ }^{65}$, Zuibarrutia, Cuartango y Ribera.

En el texto se calcula el montante anual de las cuartas empeñadas en 800 morabetinos. En el caso de percibir menos Lope Díaz de Haro cobraría dicha cantidad. Si percibiera más el resto se descontaría del montante total adeudado. Además, se menciona la existencia de algunas rentas no especificadas que, si quedaran libres, debería percibir el noble para acelerar la amortización de la deuda ${ }^{66}$. ¿Podría tratarse de los arciprestazgos alaveses no referidos en el documento, Gamboa y Orduña?

Dos son las cuestiones que podemos inferir de ambos documentos. En primer lugar, que la práctica de empeñar las rentas eclesiásticas era habitual para la devolución de préstamos pecuniarios de la nobleza. En los dos documentos se mencionan cuatro casos: los de Gonzalo de Hornillos y Lope Díaz de Haro, pero también los de Guillem Durán y don Pascual. Estas actividades, muy beneficiosas para los nobles prestamistas, al obtener no sólo la amortización de la deuda sino también otros beneficios o posesiones de naturaleza eclesiástica, reflejan una posición de debilidad por parte del obispado. Una debilidad justificable tanto por acuciantes necesidades económicas que debían paliar con estos préstamos, como por dificultades para recaudar los censos del territorio, lo que facilitaba su arriendo.

En segundo lugar, que el valor aproximado del arriendo de las cuartas episcopales de Álava pasó de 500 morabetinos en 1173 a 800 en 1229. Si

\footnotetext{
${ }^{60}$ Llorente 1808, pp. 211, 212.

${ }^{61}$ Dado que el documento fue firmado en el monasterio riojano de Cañas "más allá del Ebro" debe entenderse como "al norte del Ebro".

${ }^{62} \mathrm{Ibda}$ en el texto.

${ }^{63}$ Trokoniz, Hijona, Egileta, los actuales despoblados de Uriarte y San Román y otras cuatro aldeas a Guillem Durán; Audikana y los actuales despoblados de Luzcando, Alborcoin y Legredana? a don Pascual.

${ }^{64}$ Alaua en el texto.

${ }^{65}$ Zuhigutia en el texto.

${ }^{66}$ Rodríguez R. de Lama 1989, pp. 92-93.
} 
bien la comparación debe ser considerada con cautela, ya que ambos documentos no hacen referencia exactamente al mismo territorio, puede sugerir un aumento considerable del control episcopal de los censos de las iglesias locales alavesas, a costa de los poderes nobiliarios y monasteriales, durante estos 50 años.

\subsubsection{Problemas en el cobro de censos}

El tercer obstáculo al que se enfrentó el obispado en su proceso de afirmación a escala local fue el de los problemas de cobro de sus diferentes censos eclesiásticos. Basten los siguientes documentos fechados en el siglo XIII para ilustrar dicha situación.

En el primero, de 1222, el prelado Juan Pérez se queja ante el rey de Castilla Fernando III por las dificultades que tenía para cobrar las cuartas y los matrimonios en Ayala ${ }^{67}$. En el segundo, de 1264, el obispo Vivián llega a una concordia con los parroquianos de Villanueva de la Oca, Coscojo, Berantevilla y Arganzón ${ }^{68}$ por la que pagarían unas cantidades fijas en especie en vez de las cuartas episcopales ${ }^{69}$.

Los tres últimos documentos son concordias, datadas hacia 1275 y en 1276, entre el obispo Esteban de Sepúlveda (1273-1280) y los clérigos de varios arciprestazgos alaveses, quienes deciden retomar una actitud obediente y poner fin a sus reticencias al pago de los impuestos de catedrático y sinodático ${ }^{70}$. Todos los clérigos debían pagar estos impuestos al prelado: el catedrático como prueba de sumisión a su autoridad doctrinal y jurídica y el sinodático en señal de obediencia y en reconocimiento de su facultad para convocarlos a sínodo ${ }^{71}$.

Estos documentos matizan, por lo tanto, una imagen triunfalista de la diócesis de Calahorra y muestra problemas efectivos en el cobro de censos en las décadas centrales del siglo XIII. En cualquier caso, la capacidad del obispo para alcanzar estas concordias y asegurarse el cobro de dichos impuestos, que eran una afirmación explícita de su autoridad, es buen reflejo de su creciente influencia y poder.

\footnotetext{
${ }^{67}$ Rodríguez R. de Lama 1979, pp. 268-269.

${ }^{68}$ Sólo la primera de estas aldeas ha sobrevivido hasta nuestros días. El resto son despoblados localizados en el entorno de La Puebla de Arganzón.

${ }^{69}$ Rodríguez R. de Lama 1989, pp. 260-262; Sáenz de Haro 2012, p. 734, nota al pie n. ${ }^{\circ} 2876$.

${ }^{70}$ En concreto, el primer texto ( $c a .1275$ ), es con los clérigos del arciprestazgo de Eguilaz (ya referido), el segundo (5 julio 1276) con los del arciprestazgo de la Ribera y el tercero (8 julio 1276) con los del arciprestazgo de Gamboa y Cigoitia; Rodríguez R. de Lama 1989, pp. 303-305, 313, 315-316.

${ }^{71}$ Sáenz de Haro 2012, p. 839.
} 


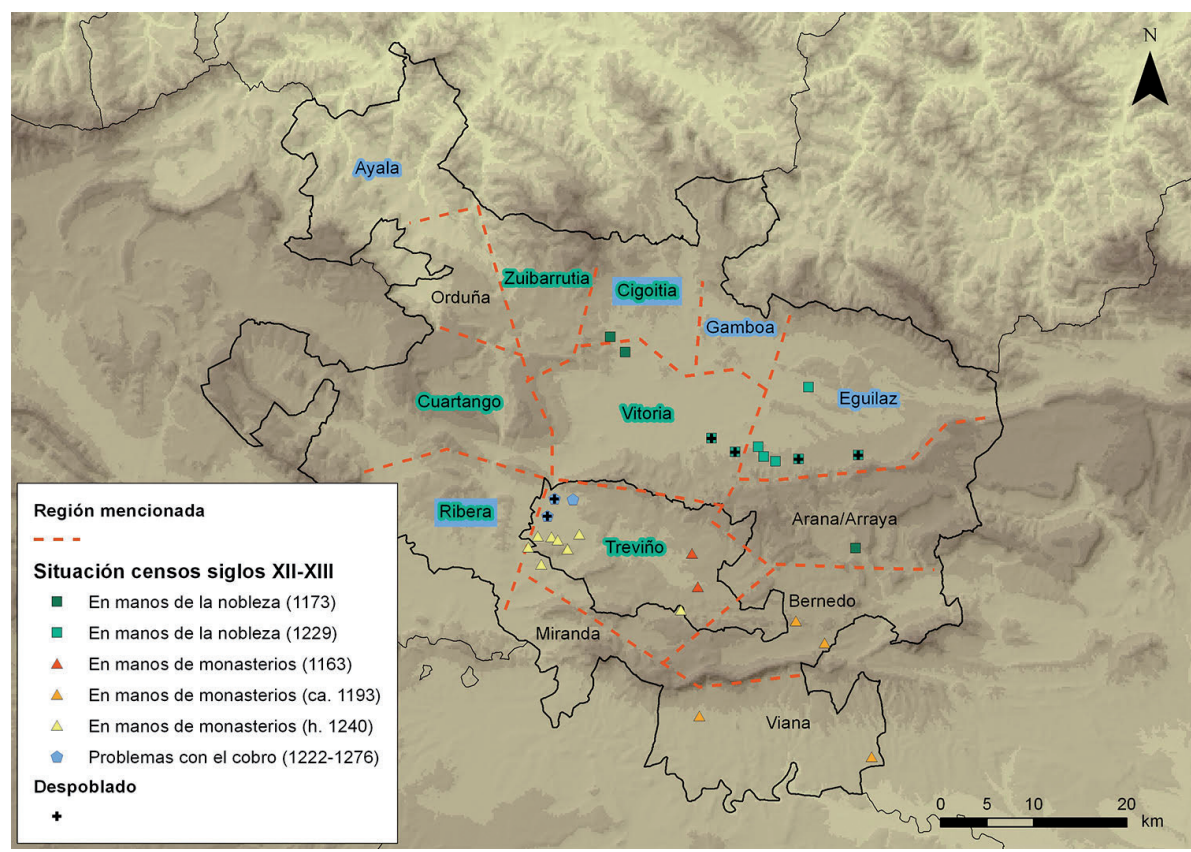

Fig. 4. Mapa con las iglesias y regiones de Álava afectados por los obstáculos con los que tuvo que lidiar la diócesis de Calahorra a nivel micro durante los siglos XII y XIII ${ }^{72}$.

\section{CONCLUSIONES}

En síntesis, el principal corolario que se infiere de la documentación consultada es que la extensión del poder episcopal en Álava fue un proceso con ritmos y resultados diferentes en función de la escala de análisis empleada. A nivel macro se infiere un rápido éxito de la diócesis calagurritana, que consiguió imponer una jerarquía administrativa sobre el territorio apenas unas décadas después de los concilios reformistas de finales del siglo XI. Una centuria antes de la detallada concordia de 1257 los documentos de 1135 y 1156 evidencian ya la existencia de dicha jerarquía, aunque sin referirse explícitamente a arciprestazgos.

Al descender a la escala local, sin embargo, comprobamos que la diócesis se topó con numerosos problemas en la tarea de controlar de forma

${ }^{72}$ Las fronteras de las regiones se han dibujado a partir de las de los arciprestazgos de 1257. La localización de algunos despoblados es aproximada y se fundamenta en los trabajos citados (véase Fig. 2). 
efectiva las iglesias y sus censos, habida cuenta de que estas se encontraban bajo la autoridad de monasterios, familias nobiliarias y comunidades aldeanas. Los principales obstáculos con los que tuvo que lidiar la administración diocesana fueron tres: el control por parte de monasterios de diferente entidad de las iglesias locales y sus censos; la devolución de préstamos a la nobleza, que afectaba al control efectivo de las rentas eclesiásticas por parte del obispado; y, finalmente, los problemas en el cobro de estas.

Esta conflictividad a nivel micro se dilató durante el siglo XII y buena parte del siglo XIII ${ }^{73}$ y está corroborada por los distintos concilios posteriores a la Reforma Gregoriana, que se refieren a los abusos e intromisiones por parte de los laicos en cuestiones eclesiásticas o directamente a sus ataques contra bienes y personas de la Iglesia ${ }^{74}$. Así, en el concilio de Burgos de 1117 se promulgaron 16 cánones que muestran que, pese a toda la obra reformista anterior, aún se producía abusos ${ }^{75}$. Son dignos de mención, igualmente, el concilio de Palencia de 1129, que prohibía la posesión hereditaria de iglesias y de los 84 pasos alrededor de las mismas, o las asambleas conciliares de Lérida en 1155 y 1173 , que trataron de frenar los abusos cometidos por los laicos en relación a la percepción de diezmos ${ }^{76}$.

En relación a esta última cuestión, J. R. Díaz de Durana y E. Guinot coinciden en que la centuria entre mediados del siglo XII y mediados del XIII fue en Castilla y Navarra especialmente conflictiva en lo que al cobro y reparto del diezmo se refiere. Los obispados impusieron progresivamente su autoridad, como atestiguan los acuerdos firmados con nobles, monasterios y órdenes militares, aunque las resistencias y oposiciones continuaron ${ }^{77}$.

Resulta de interés la importancia, subrayada por J. Eldevik, del diezmo como instrumento para definir la autoridad episcopal, al ser un símbolo único del poder diocesano, en el periodo que se abre a partir de la segunda

\footnotetext{
${ }^{73}$ Aunque con menor intensidad, los conflictos continuaron durante la Baja Edad Media. En este periodo pervivieron parroquias bajo poderes monásticos o laicos con el derecho de patronato, que implicaba fundamentalmente dos privilegios: uno de tipo económico (participación en los bienes integrantes del beneficio, especialmente en los diezmos) y otro de índole jurídico (facultad de presentar clérigos para ocupar los diversos beneficios o capellanías de estas iglesias). Este derecho se consolidó con el reconocimiento de las colecciones canónicas de los siglos XII y XIII y se mantuvo durante toda la Edad Media; Fernández Conde 1987, p. 44.

${ }^{74}$ Fernández Conde 1982, p. 431.

${ }^{75}$ Vizuete 1988, p. 334. J. A. Calvo destaca la importancia del Concilio de Burgos de 1117 por dos cuestiones. Uno, constata la presencia de ciertos abusos por parte de laicos sobre las iglesias peninsulares después del periodo de reforma. Dos, muestra que, a pesar de la importante actuación de la Reforma Gregoriana en la península ibérica, fueron notables las resistencias sociales y eclesiásticas para hacerla efectiva. Resistencias que se extendieron hasta la Baja Edad Media; Calvo 2015, pp. 224.

${ }^{76}$ Ibidem, pp. 431, 440-441.

${ }^{77}$ Díaz de Durana, Guinot 2010, pp. 67-68, 75-77.
} 
mitad del siglo XI. El autor defiende cómo, en el ámbito del Imperio Germano y a partir de 1050, los derechos diezmales adquirieron nuevos significados en la construcción de la identidad señorial de lo los obispos. Por ello, buena parte del proceso reformista se orientó a reorganizar y consolidar el control episcopal sobre los diezmos, ya que el dominio que laicos y monasterios tenían sobre ellos era un persistente recordatorio de los límites del poder diocesano. La conflictividad que surgió de este cambio de actitud no fue tanto porque estuvieran en juego meros recursos económicos, sino por el poder social subyacente en el control sobre la tierra y los individuos que la poblaban ${ }^{78}$.

En cualquier caso, reducir el enfrentamiento entre los diversos actores de esta conflictividad a una lucha polarizada entre las diócesis y el resto (monasterios, nobleza y, probablemente, comunidades aldeanas) sería un error. Más bien habría que entender el mapa parroquial del siglo XII como un complejísimo tapiz en el que estas fuerzas estaban en continua interrelación y en el que la colaboración o el enfrentamiento parecía decidirse, más que por calculadas estrategias largoplacistas, por intereses personales y coyunturas concretas, facilitando la formación de alianzas teóricamente contrapuestas .

Por otra parte, y a tenor de la documentación consultada, no existen muchas dudas sobre el aumento de la autoridad episcopal sobre las iglesias locales alavesas durante el siglo XII. Apuntan en esta dirección tres cuestiones. Primero, el crecimiento del valor aproximado del arriendo de las cuartas episcopales, que se advertía al comparar los documentos de 1173 y 1229 . Segundo, la presencia en la concordia de 1257 de iglesias bajo control de la diócesis que en documentos anteriores, de 1163 y ca. 1193, habían estado sometidas a los monasterios de San Millán o Nájera. Tercero, la propia naturaleza de las escrituras de 1240, 1264, ca. 1275 y 1276, al revelar cesiones de diversos poderes en beneficio del obispo.

Finalmente, la afirmación del poder episcopal sobre las iglesias locales es, como se ha dicho, el aspecto más visible documentalmente del proceso de implantación parroquial, por lo que resulta probable que este contara en Álava con unas características y cronologías similares a las expuestas. El registro textual, al fundamentarse en documentos elaborados por o para poderes de diferente naturaleza, ofrecen una visión desde arriba hacia abajo del fenómeno, subrayando el encuadramiento diocesano que se llevó a cabo dentro de la legitimidad del marco de la reforma gregoriana e interactuando continuamente con otros poderes territoriales y propietarios.

También las fuentes arqueológicas, con las que el autor ha trabajado para esta misma problemática, aportan unas conclusiones similares a las

${ }^{78}$ Eldevik 2012, pp. 3, 16-17, 256-257. 
expuestas: un modelo altomedieval basado en propietarios privados ajenos a la jerarquía eclesiástica, un siglo XII de transición y, finalmente, un siglo XIII de dominio diocesano a través de la institución parroquial ${ }^{79}$. Resultados similares alcanzados desde una visión distinta pero complementaria, de abajo hacia arriba y que reflejan los cambios en el seno de las identidades aldeanas.

\section{BIBLIOGRAFÍA CITADA}

\section{FUENTES PRIMARIAS}

Becerro Galicano Digital de San Millán de la Cogolla, www.ehu.eus/galicano [consulta: 06/02/2018].

Llorente, Juan Antonio (1808), Noticias históricas de las tres provincias vascongadas: Álava, Guipúzcoa y Vizcaya. Parte III. Apéndice o colección diplomática, Madrid, Imprenta Real.

Pozuelo, Felipe (2013), Colección documental de la Cuadrilla Alavesa de Zuia. II. Archivos municipales de Arratzua-Ubarrundia y Legutio. Fuentes documentales medievales del País Vasco 149, San Sebastián, Eusko Ikaskuntza.

Rodríguez R. de Lama, Ildefonso (1979), Colección diplomática medieval de La Rioja. Tomo III: Documentos (1168-1225), Logroño, Gobierno de La Rioja, Instituto de Estudios Riojanos.

Rodríguez R. de Lama, Ildefonso (1989), Colección diplomática medieval de La Rioja. Tomo IV: documentos del siglo XIII, Logroño, Gobierno de La Rioja, Instituto de Estudios Riojanos.

Rodríguez R. de Lama, Ildefonso (1992), Colección diplomática medieval de La Rioja. Tomo II. Documentos (923-1168), 2. ${ }^{a}$ edición revisada y aumentada, Logroño, Gobierno de La Rioja, Instituto de Estudios Riojanos.

\section{REFERENCIAS BIBLIOGRÁFICAS}

Alfaro, Egoitz (2016), La formación de la red parroquial en Álava y Treviño. Evidencias desde la arqueología (siglos XI-XIII), Universidad del País Vasco/Euskal Herriko Unibertsitatea (tesis doctoral inédita).

${ }^{79}$ Alfaro 2016; Alfaro, et al. 2017; Alfaro 2017; Alfaro 2020. 
Alfaro, Egoitz (2017), La arquitectura eclesiástica en Álava y Treviño durante los siglos XII-XIII: promotores, constructores y significados en un momento de transición, "Arqueología de la Arquitectura" 14, e057, doi: http://dx.doi.org/10.3989/arq.arqt.2017.010

Alfaro, Egoitz (2020), Iglesia, cementerio y aldea en Álava durante el siglo XII. ¿Evidencias materiales de la implantación parroquial?, "SPAL" 29.1, pp. 1-20.

Alfaro, Egoitz; Loza, Miguel; Niso, Javier; Solaun, José Luis (2017), Iglesias, rentas y sistemas de almacenamiento en el País Vasco durante los siglos X y XI d. C.: el testimonio arqueológico de San Martín de Dulantzi (Alegría-Dulantzi, Álava), "Archivo Español de Arqueología" 90, pp. 247-270.

Blair, John (2005), Les recherches récentes sur la formation des paroisses en Angleterre: similitudes et différences avec la France, "Médiévales" 49, pp. 33-44.

Calvo, José Antonio (2015), Rasgos de la reforma del clero en la Península Ibérica durante el siglo XI, "Studia Historica. Historia Medieval" 33, pp. 201-232.

Carl, Carolina (2008), The Bishop and the Basques: The Diocese of Calahorra and the Basque Provinces of Alava and Vizcaya under Bishop Rodrigo Cascante, 1147-1190, "Journal of Medieval History" 34, pp. 229-244.

Carl, Carolina (2011), A Bishopric Between Three Kingdoms. Calahorra 1045-1190, Leiden, Boston, Brill.

Carriedo, Manuel (2002), Cronología de los obispos de Castilla en los siglos VIII-X (Osma-Muño, Veleya-Valpuesta y Oca-Burgos), "Edad Media. Revista de Historia" 5, pp. 69-116.

Díaz de Durana, José Ramón; Guinot, Enric (2010), La dîme dans l'Espagne médiévale, en Viader, Roland (ed.), La dîme dans l'Europe médiévale et moderne. Actes des XXX ${ }^{e s}$ Journées Internationales d'Histoire de l'Abbaye de Flaran, 3 et 4 octobre 2008, Toulouse, Presses Universitaires du Mirail, pp. 63-88.

Eldevik, John (2012), Episcopal Power and Ecclesiastical Reform in the German Empire. Tithes, Lordship, and Community, 950-1150, Cambridge, Cambridge University Press.

Faci, Javier (1982), La reforma gregoriana en Castilla y León, en GarcíaVilloslada, Ricardo (ed.), Historia de la Iglesia en España, Tomo II1, La Iglesia en la España de los siglos VII al XIV, Madrid, Editorial Católica, pp. 262-275.

Fernández Conde, Francisco Javier (1982), Los concilios de la época posgregoriana. La reforma del clero secular y de las instituciones pasto- 
rales, en García-Villoslada, Ricardo (ed.), Historia de la Iglesia en España, Tomo II-1, La Iglesia en la España de los siglos VII al XIV, Madrid, Editorial Católica, pp. 426-441.

Fernández Conde, Francisco Javier (1987), La iglesia de Asturias en la Baja Edad Media: estructuras económico-administrativas, Oviedo, Instituto de Estudios Asturianos.

Fernández Conde, Francisco Javier (2000), La religiosidad medieval en España. Alta Edad Media (siglos VII-X), Oviedo, Universidad de Oviedo.

Flórez, Enrique (2007), España sagrada. Tomo XXVI. Iglesias de Auca, Valpuesta y Burgos. Madrid, Editorial Agustiniana (primera edición de 1771).

Fortún, Luis Javier (2001), El señorío monástico altomedieval como espacio de poder, en Los espacios de poder en la España medieval (XII Semana de Estudios Medievales de Nájera 2001), Logroño, Gobierno de La Rioja, pp. 239-241.

García de Cortázar, José Ángel (1988), La sociedad rural en la España medieval, Madrid, Siglo XXI de España.

García de Cortázar, José Ángel (2008), La organización socioeclesiológica del espacio en el norte de la Península Ibérica en los siglos VIII al XIII, en Sesma, José Ángel; Laliena, Carlos (eds.), La pervivencia del concepto. Nuevas reflexiones sobre la ordenación social del espacio en la Edad Media, Zaragoza, Universidad de Zaragoza, pp. 13-56.

García de Cortázar, José Ángel (2012), Historia religiosa del Occidente medieval (años 313-1464), Madrid, Akal.

González de Viñaspre, Roberto (2007), El entorno de La Puebla de Arganzón: notas históricas y lingüísticas, "Euskera" 52/3, pp. 1143-1155.

González de Viñaspre, Roberto; Uribarrena, Pedro (2012), Despoblados medievales del Condado de Treviño, en Viaje a Íbita. Estudios históricos del Condado de Treviño, Condado de Treviño, Ayuntamiento, pp. 428-450.

González Mínguez, César (1977), Aportación a la historia eclesiástica de Vitoria en la Edad Media, "Príncipe de Viana" 148-149, pp. 447-476.

Larrea, Juan José (2007), La herencia vasca: acción política y arquitectura social en Vizcaya y Álava antes de su incorporación al reino de Alfonso VI, en Fernández González, Etelvina; Pérez Gil, Javier (dirs.), Alfonso VI y su época, I, Los precedentes del reinado (966-1065), León, Universidad de León, pp. 69-119.

López de Guereñu, Gerardo (1989), Toponimia alavesa seguido de mortuorios o despoblados y pueblos alaveses, Bilbao, Euskaltzaindia. 
Loring, María Isabel (1987), Nobleza e iglesias propias en la Cantabria altomedieval, "Studia Histórica. Historia Medieval" 5, pp. 89-120.

Mañaricua, Andrés Eliseo de (1964), Obispados de Álava, Guipúzcoa y Vizcaya hasta la erección de la diócesis de Vitoria. Victoriensia, publicaciones del Seminario de Vitoria, vol. 19, Vitoria, Eset.

Martín Viso, Iñaki (1999), Organización episcopal y poder entre la Antigüedad Tardía y el Medievo (siglos V-XI): las sedes de Calahorra, Oca y Osma, "Iberia" 2, pp. 151-190.

Martínez Díez, Gonzalo (1984), Los obispados de la castilla condal hasta la consolidación del obispado de Oca en Burgos en el Concilio de Husillos (1088), en López Santidrián, Saturnino (ed.), El factor religioso en la formación de Castilla, Burgos, Aldecoa, pp. 87-164.

Martínez Díez, Gonzalo (1998), El monasterio de San Millán y sus monasterios filiales. Documentación emilianense y diplomas apócrifos, "Brocar" 21, pp. 7-53.

Martínez Díez, Gonzalo (2004), Desde la invasión musulmana hasta el traslado de la sede de Oca a Burgos: 711-1081, en Bartolomé Martínez, Bernabé (coord.), Historia de las Diócesis Españolas 20. Iglesias de Burgos, Osma-Soria y Santander, Madrid, Biblioteca de Autores Cristianos, pp. 13-41.

Núñez de Cepeda, Marcelo (1931), Hospitales vitorianos. El Santuario de la Santísima Virgen de Estíbaliz, El Escorial, Monasterio.

Peña, Esther (1995), La atribución social del espacio en la Castilla altomedieval. Una nueva aproximación al feudalismo peninsular, Santander, Universidad de Cantabria.

Pérez, Mariel (2017), Proprietary Churches, Episcopal Authority and Social Relationships in the Diocese of León (Eleventh-Twelfth Centuries), "Journal of Medieval Iberian Studies", doi: http://dx.doi.org/10.1080 /17546559.2017.1315645

Quirós, Juan Antonio (2011), Las iglesias altomedievales en el País Vasco. Del monumento al paisaje, "Studia Historica. Historia Medieval" 29, pp. 175-205.

Reglero, Carlos (2008), Cluny en España. Los prioratos de la provincia y sus redes sociales (1073 - ca. 1270), León, Centro de Estudios e Investigación San Isidoro.

Risco, Manuel (2009), España sagrada. Tomo XXXIII. Antigüedades civiles y eclesiásticas de Calahorra y obispados de Nájera y Álava, Madrid, Editorial Agustiniana (primera edición de 1771).

Sáenz de Haro, Tomás (2012), Calahorra y su entorno rural (1045-1295). Expansión demográfica y económica e implantación y transformaciones de las estructuras feudales en una ciudad de la fronte- 
ra castellano-navarra, Universidad de Salamanca (tesis doctoral inédita).

Santos, Igor (en prensa), Nuevas diócesis en antiguos territorios: reflexiones en torno al norte de Italia e Hispania (ss. VI-XI), en Martín Viso, Iñaki (ed.), La construcción de la territorialidad en la Alta Edad Media: poderes centrales y sociedades locales, Salamanca, Universidad de Salamanca.

Sharpe, Richard (1992), Churches and Communities in Early Medieval Ireland: Towards a Pastoral Model, en Blair, John; Sharpe, Richard (eds.), Pastoral Care before the Parish, Leicester, Leicester University Press, pp. 81-109.

Vizuete, José Carlos (1988), La Reforma Gregoriana en Castilla a través de las disposiciones conciliares, en Estudios sobre Alfonso VI y la reconquista de Toledo. Actas del II Congreso Internacional de Estudios Mozárabes (Toledo, 20-26 Mayo 1985), Toledo, Instituto de Estudios Visigótico-Mozárabes, pp. 321-335.

Wood, Susan (2006), The Proprietary Church in the Medieval West, Oxford, Oxford University Press.

Yarza, Joaquín (1997), Fuentes de la Historia del Arte I, Madrid, Historia 16.

Fecha de recepción del artículo: febrero 2018

Fecha de aceptación y versión final: diciembre 2018 